\title{
PREPARAÇÃO DE HIDRAZONA E $N$-ACILIDRAZONA USANDO FÁRMACOS COMERCIAIS COMO REAGENTES: AULAS PRÁTICAS DE SÍNTESE DE COMPOSTOS BIOATIVOS
}

\author{
Isabella Elias Arrudaa, Brendo Vinícius Santos Macedoa, Joseane da Conceição Macedoa, Wesley Randson Alcantara \\ Campos $^{\mathrm{a}}$, Cleônia Roberta Melo Araújo, ${ }^{*, a,([)}$ e Arlan de Assis Gonsalves ${ }^{\mathrm{a}}$ \\ Colegiado de Ciências Farmacêuticas, Universidade Federal do Vale do São Francisco, Campus Petrolina Centro, 56304-917 \\ Petrolina - PE, Brasil
}

Recebido em 05/09/2019; aceito em 07/01/2020; publicado na web em 16/03/2020

\begin{abstract}
PREPARATION OF HYDRAZONE AND $N$-ACYLHYDRAZONE USING COMMERCIAL DRUGS AS REAGENTS: PRACTICAL CLASSES OF BIOACTIVE COMPOUND SYNTHESIS. Several scientific works demonstrate the chemical and medicinal importance of hydrazone compounds. In this regard, the present paper proposes some practical classes of chemoinformatics and organic chemistry, using investigative and illustrative strategies, to teach the synthesis of a hydrazone and a $N$-acylhydrazone with proven biological activity. The motivating element used for the development of this didactic material was the use of commercial drugs, such as hydralazine and isoniazid, as alternative reagents for the synthesis of the target compounds. The sequence of experimental classes was planned to demonstrate the role of chemistry in the development of new drugs, to estimulate the curiosity of undergraduate students and to facilitate learning and the assimilation of the contents.
\end{abstract}

Keywords: hydralazine; isoniazid; Lipinski; Molinspiration; Osiris.

\section{INTRODUÇÃO}

Compostos orgânicos que possuem em sua estrutura química uma porção hidrazona e $\mathrm{N}$-acilidrazona, têm sido relatados como substâncias promissoras frente à inibição das enzimas $\mathrm{COX}$ (ciclooxigenase) e 5-LO (5-lipooxigenase). ${ }^{1}$ Em 2017, Hussain e Ali ${ }^{2}$ relataram que derivados hidrazônicos apresentam um amplo espectro de atividades farmacológicas e biológicas de interesse, e reforçaram que a busca por novas estruturas químicas desta classe pode levar ao desenvolvimento de novos fármacos com finalidades terapêuticas diversas. Assim, é válido dizer que tais substâncias podem se tornar compostos-protótipos interessantes para serem estudados pela Química Medicinal. ${ }^{1}$

Em 2018, Thota e colaboradores ${ }^{3}$ descreveram uma série de compostos sintetizados da classe das $\mathrm{N}$-acilidrazonas que exibiram atividades biológicas para diferentes alvos terapêuticos, e que já estão em fase de estudos pré-clínicos e clínicos. Os autores também citam diversos fármacos, que já foram aprovadas e vêm sendo utilizados em vários países, os quais contêm um fragmento $N$-acilidrazona em sua estrutura química, tais como a nifuroxazida (antisséptico intestinal), o dantrolene (relaxante muscular) e o carbazocromo (anti-hemorrágico).

As hidrazonas também constituem uma importante classe de intermediários sintéticos, sendo usadas em análises químicas visando à identificação de compostos carbonílicos e como complexantes de cátions metálicos. ${ }^{4}$ Pesquisas recentes também demonstram que tais compostos podem ser usados como máquinas e interruptores moleculares, devido à propriedade de isomerização reversível $E / Z$, provocada pela ligação azometina $(\mathrm{C}=\mathrm{N})$, e induzida por radiação $U V^{5}$

Desta forma, considerando a importância química e medicinal de hidrazonas e $N$-acilidrazonas (Figura 1), o presente artigo traz a proposição de aulas práticas de síntese de substâncias representativas destas classes, usando estratégias investigativas e ilustrativas, que possam ser facilmente ministradas durante as disciplinas de Química Orgânica e/ou Química Medicinal, e em cursos de Graduação em Química, Engenharia Química e Farmácia. A realização dessas práticas também possibilitará ao professor trabalhar com softwares

*e-mail: cleonia.araujo@univasf.edu.br online de uso gratuito de quimioinformática (Molinspiration e Osiris) que predizem alguns aspectos de bioatividade e toxicidade para compostos-teste, assim como fazer uma abordagem contextualizada sobre a reação clássica de síntese de hidrazonas, a qual possui grande relevância na Química.

Pode-se, ainda, citar como elemento motivador para o desenvolvimento deste material didático o uso de fármacos comerciais (hidralazina 3 e isoniazida 4) como matérias primas principais (reagentes alternativos) para a síntese dos compostos hidrazônicos almejados (Figura 1).

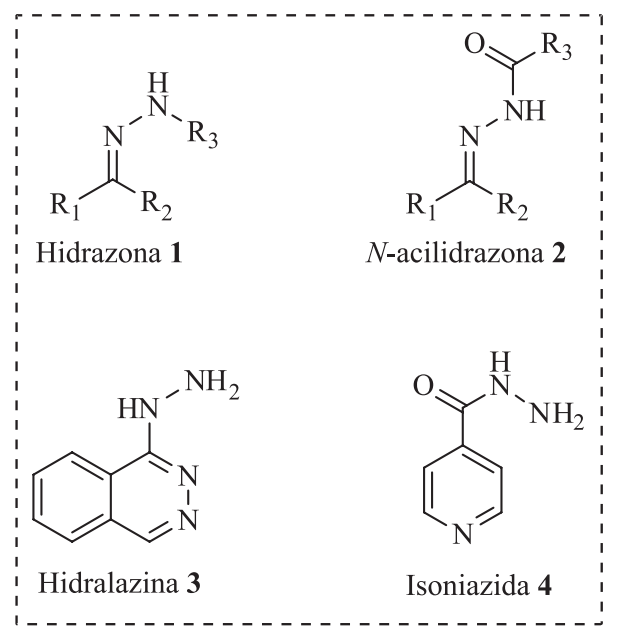

Figura 1. Esquema mostrando a estrutura química geral de hidrazonas (1), $\mathrm{N}$-acilidrazonas (2) e os fármacos hidralazina (3) e isoniazida (4)

\section{ASPECTOS TEÓRICOS}

\section{Hidrazonas e $N$-acilidrazonas}

As hidrazonas compõem uma classe de compostos com estrutura geral: $\mathrm{R}_{1} \mathrm{R}_{2} \mathrm{C}=\mathrm{N}-\mathrm{NH}-\mathrm{R}_{3}$. São substâncias obtidas normalmente pela condensação de hidrazinas com cetonas ou aldeídos, sendo 
consideradas substâncias de derivatização clássica de compostos carbonilados. ${ }^{6,7}$ Já as $N$-acilidrazonas são derivados hidrazônicos que exibem a estrutura geral: $\mathrm{R}_{1} \mathrm{R}_{2} \mathrm{C}=\mathrm{N}-\mathrm{NH}-(\mathrm{C}=\mathrm{O})-\mathrm{R}_{3}$, sendo preparadas pela condensação de hidrazidas com compostos carbonílicos (aldeídos e cetonas). ${ }^{3}$ Essas condensações ocorrem em solventes próticos e podem ser catalisadas em meio ácido (Esquema 1). Aspectos importantes das hidrazonas e derivados a serem citados são suas propriedades estruturais variadas, facilidade de síntese e estabilidade frente à hidrólise. ${ }^{8,9}$

A ligação azometina $(\mathrm{C}=\mathrm{N})$ nas hidrazonas e $N$-acilidrazonas é responsável pela formação de isômeros geométricos $(E$ e $Z)$, e essa característica pode exercer um papel fundamental para a bioatividade normalmente apresentada por esta classe de compostos. ${ }^{10}$ A ligação azometina também é responsável por gerar o tautomerismo azo-hidrazo $\left(\mathrm{H}_{3} \mathrm{C}-\mathrm{N}=\mathrm{N}-\mathrm{R} \rightleftharpoons \mathrm{H}_{2} \mathrm{C}=\mathrm{N}-\mathrm{NH}-\mathrm{R}\right)$ em solução. ${ }^{5}$ Sugere-se ainda que a conjugação $p-\pi$ existente nos fragmentos da imina, amina e carbonila de $N$-acilidrazonas eleva a estabilidade química de tais compostos. ${ }^{11} \mathrm{O}$ fragmento característico de hidrazonas exibe um grupo imino $(\mathrm{C}=\mathrm{N})$ com caráter nucleofílico e uma amina $(\mathrm{NH})$ com nitrogênio reativo e hidrogênio ácido. Além disso, o carbono imínico apresenta tanto um caráter eletrofílico quanto nucleofílico. Tais características estruturais determinam as propriedades físicas e químicas das hidrazonas, e exercem um papel crucial em suas aplicações. ${ }^{9}$

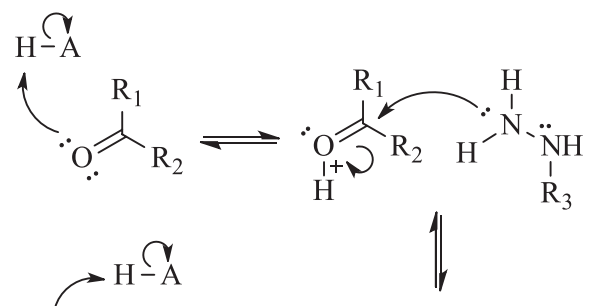<smiles></smiles>

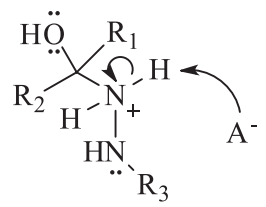

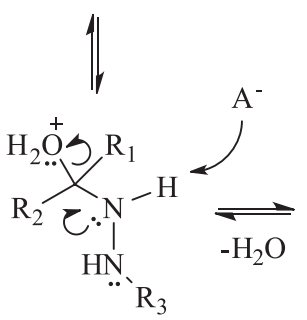<smiles>[R3]NN=C([R2])[R]</smiles>

Esquema 1. Mecanismo de formação de hidrazonas empregando a reação de condensação em meio ácido (Adaptado de Guimarães e colaboradores, 2017) ${ }^{12}$

\section{Cloridrato de hidralazina}

A hidrazina usada neste trabalho para a síntese da hidrazona almejada foi o cloridrato de hidralazina 3 , princípio ativo do medicamento comercial denominado de Apresolina ${ }^{\circledR}$. Esse fármaco exibe ação anti-hipertensiva e vasodilatadora periférica, sendo denominado quimicamente como cloridrato de 1-hidrazinilftalazina (hidralazina), e usado inclusive como redutor emergencial da pressão arterial de pacientes em crise de hipertensão. ${ }^{13}$

$\mathrm{Na}$ forma de cloridrato (sal), a hidralazina 3 é uma substância cristalina, branca (ou quase branca) e inodora, solúvel em água, pouco solúvel em etanol, e insolúvel em éter etílico e clorofórmio, com temperatura de fusão (com decomposição) em $275^{\circ} \mathrm{C}$, fórmula molecular $\mathrm{C}_{8} \mathrm{H}_{9} \mathrm{~N}_{4} \mathrm{Cl}\left(\mathrm{MM}=196,64 \mathrm{~g} \mathrm{~mol}^{-1}\right)$ e pKa 7,3 (Figura 1). ${ }^{14,15}$
O professor pode adquirir o medicamento Apresolina ${ }^{\circledR}$ em farmácias comerciais locais, na forma de drágeas de 25 ou $50 \mathrm{mg}$, e usá-las para a realização das aulas práticas. Uma caixa desse medicamento na dose de $25 \mathrm{mg}$ contém 20 drágeas, sendo um produto farmacêutico de baixo custo e fácil acesso. Recomenda-se adquirir o medicamento na dose de $25 \mathrm{mg}$, pois nesta formulação as drágeas não possuem o revestimento rosa de laca de eritrosina. Se o professor preferir, a aquisição desse fármaco como reagente puro também pode ser realizada em alguma loja especializada (Sigma Aldrich), contudo, neste caso, o mesmo normalmente é comercializado a um alto custo.

\section{Isoniazida}

A hidrazida usada neste trabalho visando a síntese das $\mathrm{N}$-acilidrazonas almejadas foi a isoniazida $\mathbf{4}$, princípio ativo do medicamento genérico de mesmo nome. A isoniazida 4 é um pró-fármaco usado como primeira escolha para o tratamento quimioterápico da tuberculose, infecção causada pelo bacilo Mycobacterium tuberculosis. ${ }^{16}$

Do ponto de vista químico, a isoniazida 4 é a hidrazida do ácido 4-piridinacarboxílico, de fórmula molecular $\mathrm{C}_{6} \mathrm{H}_{7} \mathrm{~N}_{3} \mathrm{O}$, massa molar $137,14 \mathrm{~g} \mathrm{~mol}^{-1}$, ponto de fusão $170-174{ }^{\circ} \mathrm{C}$, pKa $(2,0$ e 3,5), aspecto de um pó cristalino branco incolor, bastante solúvel em água e ligeiramente solúvel em etanol. ${ }^{14,17}$

Comprimidos de isoniazida de $100 \mathrm{mg}$ são de difícil acesso, pois se trata de um antibiótico e sua venda no Brasil é proibida no comércio, sendo dispensada gratuitamente ao paciente atendido pelo Sistema Único de Saúde (SUS) durante o tratamento da tuberculose. Contudo, o professor pode adquirir este fármaco como reagente químico puro em alguma loja especializada (Sigma-Aldrich), uma vez que esta substância possui baixo custo comercial.

\section{Molinspiration}

A ferramenta online de quimioinformática 2D denominada de Molinspiration (www.molinspiration.com) pode fazer previsões de uma série de parâmetros físico-químicos e farmacocinéticos de compostos orgânicos baseando-se na regra dos 5 de Lipinski. ${ }^{18}$ Essa regra é usada em química medicinal para auxiliar no desenvolvimento e descoberta de novos fármacos, uma vez que os parâmetros calculados visam fazer uma previsão de propriedades relacionadas à biodisponibilidade oral de substâncias químicas que serão usadas em ensaios de avaliação de atividade biológica. Essa regra propõe que a substância teste será provavelmente ativa quando administrada por via oral quando a molécula: 1) possuir menos que 5 doadores de ligação de hidrogênio (grupos $\mathrm{OH}$ e $\mathrm{NH}$ ); 2) possuir menos que 10 aceptores de ligação de hidrogênio $(\mathrm{O}$ e $\mathrm{N})$; 3) possuir peso molecular menor que $500 \mathrm{Da}$ e; 4) possuir log $\mathrm{P}$ calculado (coeficiente de partição octanol/água) menor que $5 .{ }^{19}$

Assim, os parâmetros calculados por este software são: miLogP (coeficiente de partição octanol/água), TPSA (área superficial polar topológica, expressa em $\AA$ ), n OHNH (número de doadores de ligação de hidrogênio), n ON (número de aceptores de ligação de hidrogênio), $\mathrm{n}$ violations (número de violações da regra dos 5 de Lipinski) e MW (peso molecular, expresso em Da ou $\mathrm{g} \mathrm{mol}^{-1}$ ). ${ }^{18}$

O software Molinspiration também realiza cálculos para predizer possíveis bioatividades, fornecendo um conjunto de dados teóricos que, ao serem avaliados, podem indicar alguns alvos farmacológicos dos compostos químicos em estudo. De acordo com essa plataforma de quimioinformática, um "score" calculado acima de 0,00 sugere uma considerável atividade biológica para aquele alvo específico, enquanto que valores de "score" entre - 0,50 e 0,00, indicam uma moderada atividade biológica para o alvo e, por fim, um "score" abaixo de 
$-0,50$ sugere inatividade frente ao alvo farmacológico considerado. ${ }^{19}$ Dentre os alvos farmacológicos que este programa utiliza para estimar possível bioatividade estão: atuação sobre "GPCR ligand" (receptor acoplado à proteína G), "Ion channel modulator" (modulador de canal iônico), "Kinase inhibitor" (inibidor de quinase), "Nuclear receptor ligand" (ligante de receptor nuclear), "Protease inhibitor" (inibidor de protease) e "Enzyme inhibitor" (inibidor enzimático). ${ }^{18}$

\section{Osiris}

O software Osiris (www.organic-chemistry.org/prog/peo/), ${ }^{20}$ outra ferramenta de quimioinformática 2D online, é usada para predizer o potencial toxicológico (efeitos indesejáveis) de compostos químicos orgânicos em estudo. Essa plataforma classifica o risco toxicológico de compostos-teste usando cores, em que o verde representa baixo risco, o amarelo um risco moderado, e o vermelho representa alto risco. A simulação realizada baseia-se na busca de similaridade de grupos funcionais ou de fragmentos moleculares existentes na estrutura química dos compostos-teste em relação à estrutura química e dados de ensaios toxicológicos in vitro e in vivo de substâncias já estudadas e que compõem o banco de dados do programa. ${ }^{19}$

Esse programa também disponibiliza aos seus usuários outros parâmetros físico-químicos preditos para o compostos-teste, tais como: "cLogP" (coeficiente de partição octanol/água), "Solubility" (solubilidade, expressa como LogS a partir da molaridade), "Molweight" (massa molar, expressa em $\mathrm{g} \mathrm{mol}^{-1}$ ) e "TPSA" (área superficial polar topológica). Além desses, o Osiris também fornece dois parâmetros próprios do software, que são: "Druglikeness" (um "score" que indica a presença de fragmentos moleculares no composto teste que também estão presentes em fármacos comerciais) e o "Drug-score" (um "score" que visa estimar a potencialidade deste composto em se tornar um fármaco comercial). No caso do "Druglikeness", um "score" mais positivo indica a presença de mais fragmentos de medicamentos comerciais no composto-teste. Já o valor de "Drugscore" calculado pode variar entre 0,0 e 1,0, onde o valor unitário representa uma maior potencialidade do composto-teste em se tornar um fármaco comercial. ${ }^{20}$

\section{PARTE EXPERIMENTAL}

\section{Equipamentos}

Espectros de absorção molecular UV-Vis dos compostos foram obtidos usando o Espectrofotômetro Nova Instruments (NI-1600 UV). Pontos de fusão (P.f) das substâncias sintetizadas foram registrados utilizando o Fusiômetro digital Microquímica (MQAPF-302). O perfil cromatográfico dos compostos foi avaliado usando placas de cromatografia em camada delgada (CCD) de sílica-gel $(2 \times 4 \mathrm{~cm})$, contendo indicador de fluorescência $\mathrm{GF}_{254}$., sendo calculados os respectivos fatores de retenção (R.f). Espectros de FTIR das substâncias sintetizadas foram registrados utilizando um Espectrômetro de Infravermelho com Transformada de Fourier Shimadzu (IRTracer-100, método ATR).

\section{Reagentes e materiais}

Para a realização deste trabalho foram usados os reagentes: 2-hidroxibenzaldeído (98\%, Sigma-Aldrich), isoniazida (99\%, Sigma-Aldrich), $\mathrm{H}_{3} \mathrm{PO}_{4}$ (Dinâmica), $\mathrm{NaHCO}_{3}$ (Dinâmica), álcool etílico absoluto (Dinâmica), acetato de etila (Synth) e hexano (Synth).

A fonte de hidralazina 3 usada nos experimentos foram drágeas de $25 \mathrm{mg}$ deste medicamento (Apresolina ${ }^{\circledR}$ ), o qual foi adquirido em uma farmácia local. As 20 drágeas existentes em 1 (uma) caixa deste medicamento foram pesadas e maceradas conjuntamente, e a relação fármaco/pó obtida foi de 208,85 $\mathrm{mg} \mathrm{g}^{-1}$. O pó desse medicamento (mistura de fármaco e excipientes) foi usado nas reações sem purificação.

\section{Sequência das aulas práticas}

\section{Aula prática 1: cálculos computacionais de parâmetros de bioatividade e toxicidade}

Na primeira aula prática os estudantes trabalharam em grupos e usaram seus computadores pessoais e a rede institucional para acessar pela internet os softwares computacionais Molinspiration (www. molinspiration.com) e Osiris (www.organic-chemistry.org/prog/ peo/). Usando essas ferramentas online, os estudantes desenharam nestas plataformas as estruturas químicas em 2D da hidrazona 6 e da $\mathrm{N}$-acilidrazona 7 (Figura 2), assim como dos fármacos precursores (hidralazina 3 e isoniazida 4), para se obter uma série de parâmetros moleculares calculados para tais compostos, que visam predizer, do ponto de vista teórico, o comportamento de tais substâncias em organismos vivos. Os dados obtidos para cada composto são organizados em tabelas para análise e discussão.

\section{Aula prática 2: síntese da hidrazona 6 (2-(ftalazina-1-il- hidrazonometil)-fenol)}

Em um balão de reação de $25 \mathrm{~mL}$ foram misturados $0,50 \mathrm{mmol}$ (0,0601 g) de 2-hidroxibenzaldeído 5, 0,471 g do pó do medicamento macerado de hidralazina 3 (contém o equivalente a $0,50 \mathrm{mmol}$ de fármaco), 9,0 mL de água destilada e $1,0 \mathrm{~mL}$ de $\mathrm{H}_{3} \mathrm{PO}_{4}$ concentrado (Figura 2). Essa reação foi colocada sob agitação magnética com aquecimento $\left(100^{\circ} \mathrm{C}\right.$ ) por $45 \mathrm{~min}$. Em seguida, adicionou-se $15 \mathrm{~mL}$ de etanol absoluto à mistura reacional sendo esta filtrada e o filtrado coletado em um béquer. O resíduo retido no papel foi descartado (excipientes) e sobre o filtrado foi adicionado $20 \mathrm{~mL}$ de uma solução aquosa gelada de $\mathrm{NaHCO}_{3}$ a 5,0\% $\left(\mathrm{m} \mathrm{v}^{-1}\right)$. O sólido formado foi filtrado a vácuo, lavado com etanol absoluto gelado e seco em estufa por $30 \mathrm{~min}$ a $75^{\circ} \mathrm{C}$. Após esfriar, o sólido foi removido do papel, pesado e o rendimento reacional bruto calculado.

\section{Aula prática 3: síntese da $N$-acilidrazona 7 (ácido isonicotínico (2-hidroxi-benzilideno)-hidrazida)}

Em um balão de reação de $25 \mathrm{~mL}$ foram misturados $0,50 \mathrm{mmol}$ (0,0601 g) de 2-hidroxibenzaldeído 5, 0,50 mmol (0,0686 g) de isoniazida 4, 9,0 $\mathrm{mL}$ de água destilada e $1,0 \mathrm{~mL}$ de $\mathrm{H}_{3} \mathrm{PO}_{4}$ concentrado (Figura 2). Essa reação foi colocada sob agitação magnética com aquecimento $\left(100^{\circ} \mathrm{C}\right)$ por $45 \mathrm{~min}$. Em seguida, sobre a mistura reacional foi adicionado $15 \mathrm{~mL}$ de etanol absoluto e $20 \mathrm{~mL}$ de uma solução aquosa gelada de $\mathrm{NaHCO}_{3}$ a 5,0\% $\left(\mathrm{m} \mathrm{v}^{-1}\right)$. O sólido formado foi filtrado a vácuo, lavado com etanol absoluto gelado e seco em estufa por $30 \mathrm{~min}$ a $75^{\circ} \mathrm{C}$. Após esfriar, o sólido foi removido do papel, pesado e o rendimento reacional bruto foi calculado.

\section{Aula prática 4: caracterização dos produtos de síntese}

A hidrazona 6 e a $N$-acilidrazona 7 foram caracterizadas empregando-se as técnicas de P.f, CCD, UV-Vis e FTIR. Sugere-se que essa última aula seja destinada a realizar prioritariamente as caracterizações de P.f e CCD e espectrofotometria UV-Vis. Para as análises de FTIR, dentro das possibilidades, recomenda-se que sejam realizadas previamente pelo professor, de forma que tais espectros sejam mostrados e discutidos nesta aula prática.

$\mathrm{Na}$ caracterização por espectrotofotometria UV-Vis foram preparadas soluções da hidrazona $\mathbf{6}$ e $N$-acilidrazona 7 , na concentração de $10 \mathrm{mg} \mathrm{L}^{-1}$, usando etanol absoluto:água $\left(3: 1 \mathrm{v} \mathrm{v}^{-1}\right)$ como solvente. Essa mistura de solventes também foi usada como branco. As leituras foram realizadas em cubetas de quartzo, na faixa de comprimento de 
<smiles>O=Cc1ccccc1O</smiles><smiles>[11CH3]</smiles><smiles>NNc1nncc2ccccc12</smiles>

Hidralazina 3<smiles></smiles>

Hidrazona 6 2-hidroxibenzaldeído 5<smiles>O=Cc1ccccc1O</smiles><smiles>NNC(=O)c1ccncc1</smiles>

2-hidroxibenzaldeído 5
$\mathrm{H}_{2} \mathrm{O}, \mathrm{H}_{3} \mathrm{PO}_{4}$

$45 \min , 100^{\circ} \mathrm{C}$

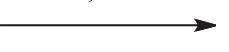

$\mathrm{H}_{2} \mathrm{O}, \mathrm{H}_{3} \mathrm{PO}_{4}$

$45 \min , 100^{\circ} \mathrm{C}$<smiles>O=C(NI)c1ccccc1CI</smiles>

N-Acilidrazona 7

Figura 2. Etapas de síntese das aulas experimentais propostas

onda de 220 a $500 \mathrm{~nm}$, e a intervalos de $10 \mathrm{~nm}$.

\section{Descarte de resíduos}

Os resíduos gerados nas aulas práticas foram armazenados em frascos separados como resíduos líquidos e sólidos, com uma etiqueta descriminando as possíveis substâncias presentes. Os fracos de resíduo de aulas práticas e pesquisa são recolhidos semestralmente pelo Suporte Técnico de Laboratórios da universidade para tratamento adequado.

\section{RESULTADOS E DISCUSSÃO}

$\mathrm{Na}$ primeira aula prática o professor explicou a um grupo de estudantes voluntários a proposta de realização de uma sequência de aulas experimentais de química visando trabalhar o seguinte conteúdo: o papel da química no desenvolvimento de novos fármacos. No primeiro momento, os estudantes foram apresentados e instruídos a usar os softwares online Molinspiration e Osiris. A manipulação desses programas de quimioinformática é gratuita e as plataformas não exigem um cadastro prévio dos usuários, o que facilita seu uso em aulas práticas de Química.

Após o professor explicar aos estudantes a regra dos 5 de Lipinski, os discentes desenharam a estrutura química 2D da hidrazona 6 e da $\mathrm{N}$-acilidrazona 7 no software Molinspiration e clicaram inicialmente na ferramenta "calculate properties". Os estudantes transferiram os dados gerados para a Tabela 1 e foram estimulados a analisar, discutir e responder ao Questionário 1 fornecido pelo professor (material

suplementar). De acordo com as respostas assinaladas, os discentes concluíram que: i) tanto a hidrazona 6 quanto a $\mathrm{N}$-acilidrazona 7 não violam a regra dos 5 de Lipinski, sugerindo que tais compostos podem exibir bioatividade por via oral; ii) os valores de "miLogP" $(<5)$ de 2,68 e 1,75 indicam que tais compostos possuem graus de lipofilicidade que facilitam suas respectivas permeabilidades através das membranas celulares; iii) os pesos moleculares da hidrazona 6 (264,29 $\left.\mathrm{g} \mathrm{mol}^{-1}\right)$ e $\mathrm{N}$-acilidrazona 7 (241,25 $\left.\mathrm{g} \mathrm{mol}^{-1}\right)$ ficaram abaixo de $500 \mathrm{Da}$ e, com isso, existe a probabilidade de que tais substâncias sejam facilmente transportadas, difundidas e absorvidas em sistemas biológicos e; iv) os parâmetros calculados de "TPSA" de 70,40 e 74,58 , bem abaixo do valor limite $(160 \AA)$, sugerem que a hidrazona 6 e a $N$-acilidrazona 7 podem exibir boa biodisponibilidade oral. Para fins comparativos, as propriedades dos fármacos precursores hidralazina $\mathbf{3}$ e isoniazida $\mathbf{4}$ também foram calculados, e os dados gerados mostraram propriedades semelhantes às exibidas pelos compostos-teste, sugerindo que as modificações estruturais realizadas não promovem alterações significativas na biodisponibilidade oral destas substâncias.

Dando continuidade à aula, os estudantes inseriram novamente as estruturas moleculares em 2D da hidrazona 6 e da $N$-acilidrazona 7 na plataforma do Molinspiration e clicaram na ferramenta "predict bioactivity". Os estudantes transferiram os dados gerados para a Tabela 2 e foram novamente estimulados a analisar, discutir e responder ao Questionário 2 fornecido pelo professor (Material Suplementar). De acordo com as respostas assinaladas, os discentes concluíram que: i) a hidrazona 6 e a $N$-acilidrazona 7 podem exibir atividade biológica,

Tabela 1. Parâmetros moleculares calculados pelo software Molinspiration usando a ferramenta "calculate properties"

\begin{tabular}{lcccccc}
\hline Composto & miLogP & TPSA & n OHNH & n ON & n violations & MW \\
\hline Hidralazina 3 & $+0,69$ & 63,83 & 3 & 4 & 4 & 0 \\
Isoniazida 4 & $-0,97$ & 68,01 & 3 & 5 & 0 & 160,18 \\
Hidrazona 6 & 2,68 & 70,40 & 2 & 5 & 0 & 264,14 \\
$N$-acilidrazona 7 & 1,75 & 74,58 & 2 & 5 & 0 & 241,25 \\
\hline
\end{tabular}

Legenda: miLogP = coeficiente de partição (octanol/água); TPSA = área superficial polar topológica $(\AA$ ) ; n OHNH = número de doadores de ligação de hidrogênio; $\mathrm{n} \mathrm{ON}=$ número de aceptores de ligação de hidrogênio; $\mathrm{n}$ violations = número de violações da regra dos 5 de Lipinski; $\mathrm{MW}=$ peso molecular $\left(\mathrm{Da}\right.$ ou $\mathrm{g}$ mol-1 ${ }^{-1}$. 
usando múltiplos mecanismos farmacológicos; ii) a hidrazona 6 mostra-se promissora para atuar inibindo, nesta ordem, quinases ("score": - 0,09), enzimas ("score": - 0,21) e "GPCR" ("score": - 0,40) e; iii) a $\mathrm{N}$-acilidrazona 7 é um composto mais promissor para atuar inibindo, nesta ordem, enzimas ("score": - 0,40) e quinases ("score": - 0,49). Segundo o Molinspiration, e considerando os compostos precursores, a hidralazina 3 parece atuar sobre, preferencialmente, enzimas ("score": -0,29), canais iônicos ("score": -0,39) e quinases ("score": -0,46). Esse fármaco é um vasodilatador de músculo liso arteriolar, com mecanismos moleculares de ação ainda não esclarecidos, mas que podem envolver alterações intracelulares do íon cálcio. ${ }^{16}$ Esse fato pode ser condizente com uma ação farmacológica sobre canais iônicos. Já a isoniazida $\mathbf{4}$ não demonstra tendência em atuar sobre os alvos farmacológicos considerados. A Farmacologia considera a isoniazida um pró-fármaco antibacteriano, cujo metabólito ativo é quem atua como inibidor da síntese de ácidos micólicos (lipídios de parede celular de micobactérias). ${ }^{16}$

Na última etapa da primeira aula prática, os estudantes acessaram o site do software Osiris, e fizeram rapidamente o download e instalação do programa em seus computadores. Os discentes desenharam a estrutura química 2D da hidrazona 6 e da $N$-acilidrazona 7 no software e, automaticamente, os dados foram gerados pelo programa. Os estudantes transferiram as informações produzidas sobre o risco toxicológico dos compostos para a Tabela 3 e foram estimulados a analisar, discutir e responder ao Questionário 3 fornecido pelo professor (material suplementar). De acordo com as respostas assinaladas, os discentes concluíram que: i) tanto a hidrazona 6 quanto a $\mathrm{N}$-acilidrazona 7 aparentam demonstrar efeitos tóxicos (indesejáveis) semelhantes; ii) que os compostos-teste provavelmente exibem alto risco para induzir a formação de tumores e de comprometer o sistema reprodutor; e iii) que tais compostos não aparentam induzir efeitos mutagênicos e irritantes. Segundo o software Osiris, os precursores hidralazina 3 e isoniazida $\mathbf{4}$ aparentam mostrar muitos efeitos tóxicos. No aspecto toxicológico, a Farmacologia relata a possibilidade de ocorrência de isquemia cardíaca e reações auto-imunes com o uso de hidralazina 3. Já a isoniazida $\mathbf{4}$ pode provocar efeitos indesejáveis como: reações de hipersensibilidade, neurotoxicidade e lesões hepáticas graves. ${ }^{16}$ Não foram encontrados relatos de efeitos tóxicos de ordem mutagênica, tumorgênica, irritante e reprodutiva provocados pelo uso desses fármacos.

Ao término dessa primeira aula prática, os estudantes se mostraram entusiasmados com a possibilidade de prever, mesmo que de um ponto de vista teórico, algumas propriedades biológicas e toxicológicas de compostos orgânicos de seu interesse. Também ficaram envolvidos e até ansiosos para as próximas aulas práticas, momento em que irão efetivamente sintetizar em laboratório as substâncias usadas como compostos-teste (hidrazona 6 e $\mathrm{N}$-acilidrazona 7) nos ensaios de quimioinformática realizados com o Molinspiration e o Osiris. A forma de execução dessa aula prática seguiu um caráter investigativo, exigindo do estudante a produção e a coleta de informações tecnológicas e a subsequente interpretação de tais dados usando o conhecimento científico.

Na segunda aula prática, os estudantes foram novamente divididos em grupos e cada um recebeu o roteiro experimental impresso. $\mathrm{O}$ professor explicou os procedimentos da prática, as fontes das matérias primas principais (fármacos comerciais) e o mecanismo da reação que os discentes iriam realizar (Esquema 1). Apesar da simplicidade da reação química envolvida (etapa única), os procedimentos experimentais em sequência que os estudantes devem efetuar nessa aula são diversos e, em cada etapa, os graduandos vão aprimorando suas habilidades técnicas laboratoriais, tais como: a pesagem e maceração de drágeas de Apresolina ${ }^{\circledR}$; cálculos, manipulação e pesagem das matérias primas em balança analítica; montagem, manipulação de reagentes e acompanhamento da reação; etapas de filtração para a separação do produto; secagem em estufa e pesagem do produto seco obtido e; por fim, o cálculo de rendimento bruto da síntese. Quase todos esses procedimentos foram realizados dentro de uma aula prática de $2 \mathrm{~h}$ e com dois grupos $(\mathrm{n}=2)$ de 3 estudantes voluntários cada. As exceções foram as etapas de pesagem do produto seco obtido e o cálculo de rendimento bruto da síntese, que os estudantes só realizaram na quarta aula prática da sequência de aulas experimentais propostas (aula de caracterização dos produtos de síntese).

Ao término da segunda aula prática os estudantes obtiveram a hidrazona 6, que foi produzida a partir da reação de condensação entre o 2-hidroxibenzaldeído 5 e a hidralazina 3, usando drágeas de Apresolina ${ }^{\circledR}$ como matéria-prima alternativa. Esse produto se mostrou como um sólido amarelo (Figura $1 \mathrm{~S}$ ), sendo que a reação realizada produziu em média $0,0361 \mathrm{~g}$ do produto bruto (sem passar por procedimentos de purificação). Considerando-se a massa molar da hidrazona $6\left(\mathrm{C}_{15} \mathrm{H}_{12} \mathrm{~N}_{4} \mathrm{O}\right)$ de $264,29 \mathrm{~g} \mathrm{~mol}^{-1}$, o rendimento reacional bruto ficou em torno de $27 \%$, sendo esse rendimento calculado em função da quantidade de matéria (em mmol) de 2-hidroxibenzaldeído 5 usado na reação. Esse valor reflete um baixo rendimento, porém, deve-se levar em conta que foi usado um material alternativo como

Tabela 2. Valores de "score" calculados para bioatividade pelo software Molinspiration usando a ferramenta "predict bioactivity"

\begin{tabular}{lcccccc}
\hline Composto & GPCR & $\begin{array}{c}\text { Ion Channel } \\
\text { modulator }\end{array}$ & Kinase inhibitor & $\begin{array}{c}\text { Nuclear receptor } \\
\text { ligand }\end{array}$ & Protease inhibitor & Enzyme inhibitor \\
\hline Hidralazina 3 & $-1,11$ & $-0,39$ & $-0,46$ & $-2,63$ & $-1,30$ & $-0,29$ \\
Isoniazida 4 & $-1,39$ & $-1,45$ & $-1,05$ & $-2,33$ & $-1,23$ & $-0,66$ \\
Hidrazona 6 & $-0,40$ & $-0,44$ & $-0,09$ & $-1,28$ & $-0,74$ & $-0,21$ \\
$N$-acilidrazona 7 & $-0,53$ & $-0,90$ & $-0,49$ & $-0,77$ & $-0,75$ & $-0,40$ \\
\hline
\end{tabular}

$\mathrm{GPCR}=$ receptor acoplado à proteína $\mathrm{G}$.

Tabela 3. Potencial de risco toxicológico predito pelo software Osiris em escala de cores

\begin{tabular}{lcccc}
\hline Composto & Mutagenic & Tumorigenic & Irritant effect & Reproductive effect \\
\hline Hidralazina 3 & vermelho & vermelho & verde & vermelho \\
Isoniazida 4 & vermelho & vermelho & vermelho & vermelho \\
Hidrazona 6 & verde & vermelho & verde & vermelho \\
$N$-acilidrazona 7 & verde & vermelho & verde & vermelho
\end{tabular}

Escala de cores: verde (baixo risco), amarelo (risco moderado) e vermelho (alto risco). 
fonte de matéria-prima da reação (drágeas de Apresolina ${ }^{\circledR}$ ), os quais continham excipientes que talvez possam ter interferido na reação. Apesar do baixo rendimento reacional, o importante é que os estudantes perceberam que o produto almejado foi sintetizado, já que a hidrazona 6 apresenta características visuais distintas das matérias-primas usadas, ou seja, o 2-hidroxibenzaldeído 5 é uma substância líquida à temperatura ambiente, o pó macerado do medicamento possui uma tonalidade bege claro, e o produto obtido exibiu uma coloração amarela. A forma de execução desta aula prática seguiu um caráter ilustrativo, exigindo do estudante uma desenvoltura técnica laboratorial já adquirida em disciplinas práticas de química cursadas anteriormente em sua graduação.

A terceira aula prática seguiu os mesmos procedimentos experimentais da anterior, contudo, o objetivo da proposta foi o de sintetizar a $\mathrm{N}$-acilidrazona 7 , a partir da reação de condensação entre o 2-hidroxibenzaldeído 5 e a isoniazida 4 (fármaco adquirido como reagente comercial com grau de pureza de $99 \%$ ). Ao término dessa aula, os estudantes obtiveram como produto reacional um sólido branco (Figura $1 \mathrm{~S}$ ), com uma massa média de $0,1073 \mathrm{~g}$ do produto bruto (sem passar por procedimentos de purificação). Considerando a massa molar da $N$-acilidrazona $7\left(\mathrm{C}_{13} \mathrm{H}_{11} \mathrm{~N}_{3} \mathrm{O}_{2}\right)$ de $241,25 \mathrm{~g} \mathrm{~mol}^{-1}$, o rendimento reacional bruto ficou em torno de $89 \%$, sendo esse rendimento também calculado em função da quantidade de matéria (em mmol) de 2-hidroxibenzaldeído 5 usado na reação. Nesse caso, os estudantes perceberam que o rendimento reacional melhorou bastante em relação à síntese da hidrazona 6 . Esse resultado sustentou a hipótese levantada na aula prática anterior, a de que os excipientes do medicamento Apresolina ${ }^{\circledR}$ prejudicaram a reação de condensação. Diante desse fato, o professor interveio na aula e pediu que os estudantes calculassem o percentual em massa dos excipientes no medicamento Apresolina ${ }^{\circledR}$, visando a construir uma explicação teórica e experimental para tais resultados. No caso das drágeas, o percentual em massa calculado para os excipientes foi de $79,1 \%$, superando bastante o teor de cloridrato de hidralazina (fármaco) presente na formulação. Já a síntese da $N$-acilidrazona 7 com isoniazida foi usada esse reagente puro (99\%), com baixíssimo percentual de impurezas. Tais dados reforçaram a hipótese dos excipientes (impurezas) terem interferido no progresso da reação da hidrazona $\mathbf{6}$, já que quando estavam presentes em maior proporção foi obtido um menor rendimento. Do ponto de vista didático, o baixo rendimento reacional obtido pelos estudantes na síntese da hidrazona $\mathbf{6}$ foi salutar, pois permitiu que eles promovessem uma reflexão racionalizada para explicar os fenômenos observados, ação importante na construção do conhecimento. Diante dessa interpretação, os estudantes ficaram mais satisfeitos, pois perceberam que os baixos rendimentos obtidos não foram, provavelmente, decorrentes de procedimentos experimentais realizados de maneira equivocada.

Na quarta aula prática, os estudantes determinaram o P.f. dos produtos de síntese preparados nas aulas anteriores, verificaram os perfis cromatográficos em camada delgada e obtiveram os espectros de absorção molecular no UV-Vis dos compostos em solução hidroalcoólica. O professor também lhes mostrou e explicou os sinais dos espectros de FTIR obtidos previamente (Figuras $3 \mathrm{~S}$ e $4 \mathrm{~S})$. Na medida em que os discentes obtinham os resultados, o professor lhes fornecia uma explicação baseando-se em pesquisa bibliográfica realizada previamente. Assim, a hidrazona 6, obtida como um sólido amarelo, mostrou P.f. variando entre 196 e $202{ }^{\circ} \mathrm{C}$, valor concordante com o relatado por Prasanna e colaboradores, ${ }^{21}$ que estabeleceram P.f de $206{ }^{\circ} \mathrm{C}$ para o tautômero hidrazinilideno deste composto. Na CCD, após solubilização dos compostos em acetona, eluição em hexano:acetato de etila $\left(3: 2 \mathrm{v} \mathrm{v}^{-1}\right)$ e revelação com iodo, o cloridrato de hidralazina 4 no pó do medicamento não deslocou-se do ponto de aplicação, porém foi fortemente corado, o 2-hidroxibenzaldeído 5 não foi revelado com iodo, e a hidrazona 6 exibiu R.f. de 0,86, corando-se moderadamente (Figura 2S). Esse resultado mostra uma maior hidrofobicidade do composto em razão de menor interação com a fase estacionária polar da placa (sílica) e maior interação com a mistura de solventes apolares que compunham o eluente. A CCD também mostrou que o produto obtido se encontrava aparentemente puro. O espectro de varredura no UV-Vis da hidrazona 6 revelou bandas com máximos de absorção em 290

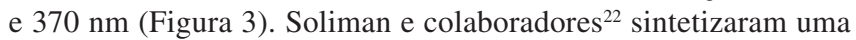
substância análoga à hidrazona 6, usando hidralazina 3 e 2-carbaldeído piridina, e obtiveram um espectro no UV-Vis bastante semelhante, também com máximos em 290 e 370 nm. Segundo estes autores, tais absorções são referentes às transições eletrônicas HOMO $\rightarrow$ LUMO $\left(\pi \rightarrow \pi^{*}\right)$ na molécula. O espectro de FTIR da hidrazona 6 mostra bandas finas de intensidade moderada, com as principais em: $3315(\mathrm{vN}-\mathrm{H}) ; 1612(\mathrm{vC}=\mathrm{N}$, azometina); 1598 e 1530 $(v \mathrm{C}=\mathrm{C}) ; 1270(\mathrm{vC}-\mathrm{O})$ e $1015 \mathrm{~cm}^{-1}(\mathrm{vC}-\mathrm{N})($ Figura $3 \mathrm{~S})$. Esses sinais são concordantes com os relatados por El-Sherif e colaboradores, ${ }^{23}$ e confirmam a síntese do produto almejado.

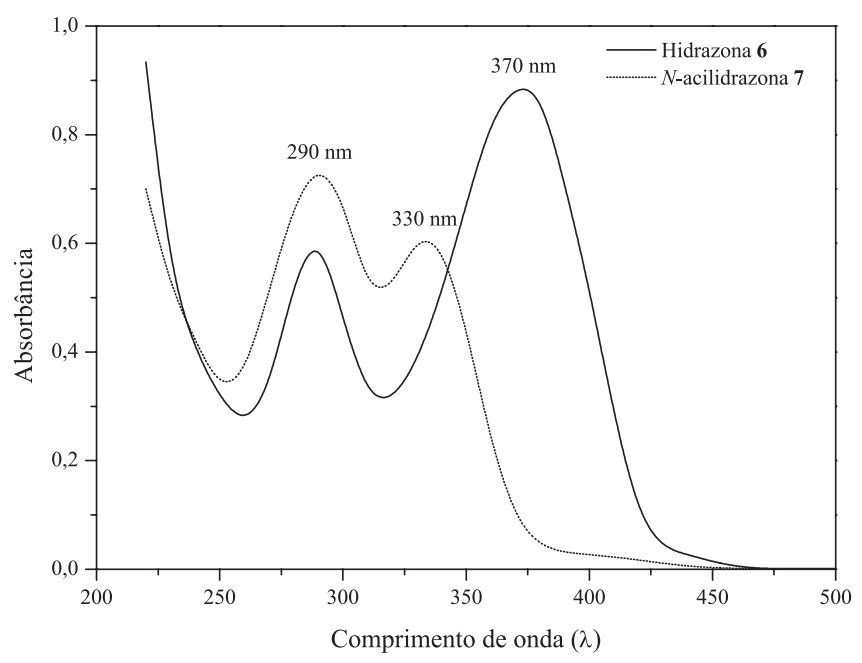

Figura 3. Espectros de absorção molecular no UV-Vis dos produtos de síntese

Ainda na quarta aula prática, a $\mathrm{N}$-acilidrazona 7 , obtida como um sólido branco, mostrou P.f. entre 239 e $242{ }^{\circ} \mathrm{C}$. O P.f. descrito na literatura para essa substância é bastante variável, sendo encontrado valores de $225{ }^{\circ} \mathrm{C},{ }^{24} 252{ }^{\circ} \mathrm{C}^{25}$ e $262-264{ }^{\circ} \mathrm{C} .{ }^{26} \mathrm{Na} \mathrm{CCD}$, nas mesmas condições experimentais para a hidrazona $\mathbf{6}$, a isoniazida 3 também não deslocou-se do ponto de aplicação (porém foi corada fortemente pelo iodo), o 2-hidroxibenzaldeído 5 não foi revelado com iodo, e a $\mathrm{N}$-acilidrazona 7 mostrou R.f de 0,18 (corando fracamente com iodo) (Figura 2S). Esse resultado revela uma menor hidrofobicidade do composto, já que sua interação com a fase estacionária polar da placa (sílica) foi maior que com o eluente apolar. A cromatografia também revelou que o produto se encontrava aparentemente puro. $\mathrm{O}$ espectro de varredura no UV-Vis da $\mathrm{N}$-acilidrazona 7 revelou bandas com máximos de absorção em 290 e 330 nm (Figura 3), sendo o perfil desse espectro bastante semelhante ao obtido por Ferraresi-Curotto e colaboradores ${ }^{9}$ para um composto análogo à $N$-acilidrazona 7 , e obtido usando isoniazida 4 e 5-clorosalicilaldeído. Segundo esses autores, a absorção em $290 \mathrm{~nm}$ é característica da $N$-acilidrazona, e refere-se à transição $\pi \rightarrow \pi^{*}$ oriunda conjuntamente do anel aldeídico orto-substituído $(-\mathrm{OH})$, do anel piridínico e da carbonila $(\mathrm{C}=\mathrm{O})$. Já a absorção em $330 \mathrm{~nm}$ pode ser atribuída à transição $n \rightarrow \pi^{*}$ dos elétrons livres dos heteroátomos de $\mathrm{Ne} \mathrm{O} .{ }^{27}$ No espectro de FTIR da $\mathrm{N}$-acilidrazona 7 são observadas diversas bandas, com as principais em: 1680 (vC=O de amida); 1626 (vN-H de amida); 1567 (vC=N, 
azometina); 1490 (vC=C); 1290 e $1274 \mathrm{~cm}^{-1}$ (vC-O) e 1159 (vC-N) (Figura 4S). Esses sinais são concordantes com os relatados por Abou-Melha,${ }^{24}$ confirmando que o produto almejado foi sintetizado.

Para a conclusão da sequência de aulas práticas propostas, informações de bioatividade já estudadas e publicadas para a hidrazona 6 e $N$-acilidrazona 7 (Quadro 1) foram repassadas aos estudantes pelo professor, para fazê-los perceber que não é obrigatoriamente necessária a realização de reações orgânicas de alta complexidade para obter possíveis substâncias bioativas e promissoras do ponto de vista farmacológico.

Quadro 1. Atividades biológicas já avaliadas e publicadas para a hidrazona 6 e $N$-acilidrazona 7

\begin{tabular}{|c|c|c|}
\hline Composto & Descrição do estudo & Referência \\
\hline Hidrazona 6 & $\begin{array}{l}\text { Atividades antimicrobianas } \\
\text { da hidrazona } 6 \text { e de seus com- } \\
\text { plexos metálicos de } \mathrm{Cu}(\mathrm{II}) \text {, } \\
\mathrm{Ni}(\mathrm{II}) \text { e } \mathrm{Co}(\mathrm{II}) \text { foram avalia- } \\
\text { das in vitro. Os resultados } \\
\text { indicaram que tanto o ligante } \\
\text { quanto os respectivos com- } \\
\text { plexos metálicos inibiram } \\
\text { moderadamente o crescimento } \\
\text { bacteriano de, principalmente, } \\
\text { bactérias gram-positivas (Sta- } \\
\text { phylococcus aureus e Bacillus } \\
\text { subtillis). }\end{array}$ & $\begin{array}{c}\text { El-Sherif e } \\
\text { colaboradores } \\
(2012)^{23}\end{array}$ \\
\hline -acilidrazona 7 & $\begin{array}{l}\text { Um estudo de toxicidade } \\
\text { aguda e avaliação de algumas } \\
\text { atividades farmacológicas } \\
\text { para a } N \text {-acilidrazona } 7 \text { e ou- } \\
\text { tros análogos foram avaliados } \\
\text { usando testes farmacológicos } \\
\text { em modelos animais (in vivo). } \\
\text { Os resultados indicaram que } \\
\text { os compostos testados não } \\
\text { promoveram reação tóxica ou } \\
\text { mortalidade, até a dose máxi- } \\
\text { ma de } 2000 \mathrm{mg} \mathrm{Kg}^{-1} \text {, e que } \\
\text { as } N \text {-acilidrazonas análogas } \\
\text { exibiram efeito antidepressivo } \\
\text { significativo e dependente } \\
\text { da dose. }\end{array}$ & $\begin{array}{c}\text { Thomas e } \\
\text { colaboradores } \\
(2016)^{25}\end{array}$ \\
\hline
\end{tabular}

\section{CONCLUSÃO}

Uma sequência de aulas experimentais foi desenvolvida visando demonstrar o papel da química no desenvolvimento de novos fármacos. A proposta apresentada, além de introduzir aspectos teóricos importantes de química orgânica e medicinal, também possibilita ao graduando vivenciar um pouco na prática alguns procedimentos que são muitas vezes repetidos na pesquisa científica voltada para a descoberta de novos compostos bioativos. Todos os experimentos descritos podem ser reproduzidos em cursos de Graduação em Química, Engenharia Química e Farmácia, usando uma infraestrutura laboratorial básica. O conjunto de experimentos executado também pode despertar a curiosidade dos graduandos e incentivá-los a se dedicarem com mais afinco às disciplinas de química orgânica e química medicinal e, sendo mais otimista, pode inclusive despertar vocações para a pesquisa científica, em nível de mestrado e doutorado, nessas importantes áreas do conhecimento.

\section{MATERIAL SUPLEMENTAR}

Os espectros de FTIR das substâncias sintetizadas, assim como outras figuras e materiais de apoio estão disponíveis em http:// quimicanova.sbq.org.br, em arquivo pdf, com livre acesso.

\section{AGRADECIMENTOS}

Os autores desejam agradecer ao $\mathrm{CNPq}$ pelas bolsas, nas modalidades PIBIC e PIVIC, recebidas por alguns estudantes de iniciação científica que participaram deste trabalho.

\section{REFERÊNCIAS}

1. Reis, S. L. G. B.; Almeida, V. M.; Almeida, G. C.; Boaviagem, K. M.; Mendes, C. C. B.; Faria, A. R.; Góes, A. J. S.; Magalhães, L. R.; Silva, T. G.; Quim. Nova 2011, 34, 76.

2. Hussain, I; Ali, A.; J. Phytochem. Biochem. 2017, 01, 104.

3. Thota, S; Rodrigues, D. A.; Pinheiro, P. S. M.; Lima, L. M.; Fraga, C. A. M.; Barreiro, E. J.; Bioorg. Med. Chem. Lett. 2018, 28, 2797.

4. AL-Thib, A. T. M.; Khudhair, N. A.; Phys. Chem.: Indian J. 2016, 11, 24.

5. Romero, E. L.; D’Vries, R. F.; Zuluaga, F.; Chaur, M. N.; J. Braz. Chem. Soc. 2015, 26, 1265.

6. Guimarães, D. G.; Rolim, L. A.; Gonsalves, A. A.; Araújo, C. R. M.; Rev. Virtual Quim. 2017, 09, 2551.

7. Barreiro, E. J.; Fraga, C. A. M.; Miranda, A. L. P.; Rodrigues, C. R.; Quim. Nova 2002, 25, 129.

8. López-Torres, E.; Zani, F.; Mendiola, M. A.; J. Inorg. Biochem. 2011, 105, 600 .

9. Ferraresi-Curotto V.; Echeverría, G. A.; Piro, O. E.; Pis-Diez, R.; González-Baro, A. C.; J. Mol. Struct. 2017, 1133, 436.

10. Singh, N.; Ranjana, R.; Kumari, M.; Kumar, B.; Int. J. Pharm. Clin. Res. 2016, $08,162$.

11. Liu, X.; Tang, Y.; He, X.; Ge, X.; Liu, J.; Meng, X.; Shao, M.; Jin, Y.; Tian, L.; Liu, Z.; J. Inorg. Biochem. 2018, 191, 194.

12. Guimarães, D. G.; Rolim, L. A.; Gonsalves, A. A.; Araújo, C. R. M.; Rev. Virtual Quim. 2017, 9, 2551.

13. Nfor, E. N.; Husian, A.; Majoumo-Mbe, F.; Njah, I. N.; Offiong, O. E.; Bourne, S. A.; Polyhedron 2013, 63, 207.

14. Brasil; Farmacopeia Brasileira, $5^{\text {a }}$ ed., v. 2, Agência Nacional de Vigilância Sanitária: Brasília, 2010.

15. Thomas, L. L.; David, A. W.; Foye's Principles of Medicinal Chemistry, $7^{\text {th }}$ ed., Lippincott Williams \& Wilkins: Philadelphia, 2012.

16. Brunton, L. L.; Lazo, J. S.; Parker, K. L.; Goodman e Gilman: As Bases Farmacológicas da Terapêutica, $11^{\mathrm{a}}$ ed., MacGraw-Hill Interamericana do Brasil: Rio de Janeiro, 2006.

17. Lima, P. C.; Albert, A. L. M.; Leandro, K. C.; Rev. Inst. Adolfo Lutz 2015, 74, 190.

18. www.molinspiration.com, acessada em Março 2020.

19. Husain, A.; Ahmad, A.; Khan, S. A.; Asif, M.; Bhutani, R.; Al-Abbasi, F. A.; Saudi Pharm. J. 2016, 24, 104

20. www.organic-chemistry.org/prog/peo/, acessada em Março 2020.

21. Prasanna, M. K.; Sithambaresan, M.; Pradeepkumara, K.; Kurupc, M. R. P.; Acta Crystallogr., Sect. E: Crystallogr. Commun. 2013, 69, 1522.

22. Soliman, S. M.; Albering, J. H.; Farooq, M.; Wadaan, M. A. M.; ElFaham, A.; Inorg. Chim. Acta 2017, 466, 16.

23. El-Sherif, A. A.; Shoukry, M. M.; Abd-Elgawad, M. M. A.; Spectrochim. Acta, Part A 2012, 98, 307.

24. Abou-Melha, K. S.; Spectrochim. Acta, Part A 2008, 70, 162.

25. Khan, M. S. Y.; Chawla, G.; Mueed, M. A.; Ind. J. Chem. 2004, 43B, 1302 .

26. Thomas, A. B.; Nanda, R. K.; Kothapalli, L. P.; Hamane, S. C.; Arabian J. Chem. 2016, 09, S79.

27. Maurya, M. R.; Saklani, H.; Kumar, A.; Chand, S.; Catal. Lett. 2004, 93, 121. 